\title{
Swim Speed Tests as a Method for Differentiating the Profiles of Young Swimmers
}

\author{
Klara Šiljeg ${ }^{1}$, Joško Sindik² and Goran Leko ${ }^{3}$
}

Affiliations: 'University of Zagreb, Faculty of Kinesiology, Croatia, ${ }^{2}$ Institute for Anthropological Research, Croatia, ${ }^{3}$ University of Zagreb, Faculty of Kinesiology, Croatia

Correspondence: Klara Šiljeg, University of Zagreb, Faculty of Kinesiology, Croatia, Horvaćanski zavoj 15, 10000 Zagreb, Croatia. E-mail: kklara.siljeg@gmail.com

ABSTRACT Swimming tests are used in every training cycle and seasons with purpose of estimating swimming performance and evaluate certain training types. The focus of this study is an attempt to distinguish between the potential short-distance and longer-distance swimmers, as well as the swimmers who could have desirable profiles for particular swimming styles. For this purpose, several aims are given: () to determine the latent dimensions of the performances in swimming tests, conducted on various distances and performed using different swimming styles; 2) to determine the correlations between speeds on various distances using different swimming styles; 3 ) to determine the differences in various distance speeds at the same swimmers; $4)$ to determine the profiles of swimmers, based on the various distance speeds (4). Male swimmers $(\mathrm{N}=68)$, aged 14 to 16 from five Zagreb clubs were tested. Four swimming tests were used to measure speed (25$\mathrm{m}$ freestyle, backstroke, breaststroke, butterfly), five swimming tests measured speed endurance (50-m freestyle, 100-m freestyle, backstroke, breaststroke, butterfly), while only one test measured endurance (800$\mathrm{m}$ freestyle). The results revealed two interpretable and highly reliable latent dimensions of swimming tests. Factor analysis of the scores in swimming tests differentiated the variables of swimming tests that describe breaststrokes and other strokes. Most of the scores in the swimming tests are positively correlated (in range $0.25-0.85$ ), while no differences in various distance speeds among the same swimmers are found. The results indicate the importance of using swimming tests, especially in breaststrokes styles, because of their specific motor structure.

KEY WORDS Breaststroke, Swimming Styles, Various Distances.

@MJSSMontenegro

SWIM SPEED TESTS

http://mjssm.me/?sekcija=article\&artid=138

\section{Introduction}

The key to success does not lie in training hard, but in training purposefully and carefully (Olbrecht, 2000). The purpose of this research is to emphasize the importance of testing the swimmers by using specific swimming tests. These tests are direct indicators of the current status of the swimmers and serve for possible changes (corrections) in the training process, as well as the orientation for directing a swimmer to train with a particular swimming technique.

\section{Swimming tests and the role of the coach}

The goal of a successful coach is to improve the performance of his swimmers, and coaches are aware that a training program has great influence on final swimming performance (Richards, 1999; Costa, 2016). Therefore, swimming coaches use the swimming tests (ST) to evaluate basic speed, stroke mechanics, starts and turning ability, the physiological factors of basic and specific endurance, anaerobic power and capacity, muscle power and flexibility and, finally, the psychological factors of motivation and stress management (Smith, Noris \& Hogg, 2002; Costa, 2016). All of that has a certain impact on the final results in swimming 
performance. To control training tasks or to obtain insight into a current state of a competing swimmer, testing during training is conducted daily. With testing, a coach can predict future competitive performance and provide recommendations for continued directional training (Smith et al., 2002).

\section{Young swimmers}

Swimmers from 14 to 16 years old conducted training in all zones of intensity, mostly in the aerobic zone, and all swimming techniques (Thorton, 2012; Vorontsov, 2002). Many scientists suggest that male swimmers' specialization begins at 13 to 16 years old (Vorontsov, 2002; Sokolovas, 2006). Timely and quality specialization would result in a longer retention of swimmers in competitive swimming and enable the full development of their potentials. It is often the case that junior swimmers are equally successful in more than one discipline, especially in swimming associations that have the smallest number of competing swimmers (Šiljeg, 2012); the same author suggests that knowing the connection between specific control tests and success in certain swimming techniques would lower the possibility of mistakes when directing a swimmer towards a certain discipline.

\section{Specifics of swimming techniques and young swimmers}

The anthropometric characteristics, the motor structure, and energy expenditure are quite different in four techniques (Barbosa et al., 2006; Leko, Šiljeg \& Zoretić, 2011). For example, a more propulsive force is made by the motion of the hand in freestyle and backstroke (Brooks, Lance \& Sawhill, 2000; Maglischo, 2003) or by undulating the body like in butterfly (Maglischo, 2003), but in the breaststroke (BS) the kick is more essential for power and efficiency (Strzała et al., 2012; Maglischo, 2003; Sweetenham, 2003). Freestyle, backstroke, and butterfly strokes require much greater mobility and range of motion because of the high demand for rotation in the shoulder joint (Bishop, Cree, Read, Chavda, Edwards \& Turner, 2013). Nuber, Jobe, Perry and Moynes (1986) provided supporting evidence to the notion of less rotational requirement in the breaststroke.

Injuries are also different according to different swim technique. Freestyle and butterfly swimmers are frequently associated with impingement syndrome in shoulders because of the repetitive nature of rotation, but this injury is not frequent in breaststroke swimmers (Nuber et al., 1986; Maglischo, 2003). In breaststroke swimmers, hip adductors, and knee joint injuries were significantly more common than in non-breaststroke swimmers (Keskinen, Eriksson \& Komi, 1980; Grote, Lincol \& Gamble, 2004). The above-mentioned expresses the controlled important especially in this critical forming age when interests are changing, and personal crisis occurs, creating the question whether to continue swimming or not (Šiljeg, 2012). Numerous authors have reported that the high prediction of swimming performance has had on specific ST in the water (Šiljeg, 2012; Latt et al., 2010; Arrelano, 2004). Hence, the ST in this research has been performed to measure: swimming speed (on the distance of $25 \mathrm{~m}$ for all four techniques), speed endurance (on the distance of $50 \mathrm{~m}$, only for the freestyle and on the distance of $100 \mathrm{~m}$ in all four techniques) and endurance (on the distance of $800 \mathrm{~m}$, only for the freestyle).

The focus of this study is an attempt to distinguish between the potential short-distance and a longer-distance swimmers, as well as the swimmers who could have desirable profiles for particular swimming styles. The various swimming strokes are quite different in terms of the patterns of muscle recruitment, the force and power produced, as well as the energy required for a given swimming speed (Nelson, Pyne \& Sweetenham, 1991). Control of progress with timely and valid specialization would ensure the maximum utilization of the genetic potential of any swimmer (Vorontsov, 2002). A breaststroker usually does not find his/her optimal swimming style spontaneously (Soons, Colman \& Persin, 2003). However, instructional intervention could significantly improve the technique and performance in certain techniques, according to Havriluk (2006). Therefore, the training process should be tailored to the individual needs of certain swimmers, according to their technique of swimming.

In order to apply the knowledge obtained by ST for improving orientation (choosing the most convenient swimming technique for each swimmer), as well as to adjust the training process to the individual specifics of each swimmer, several goals of our study were defined: first, to determine the latent dimensions of the performances in ST, conducted on various distances and performed using different swimming techniques; second, to determine the correlations between speeds on various distances using different swimming styles; third, to determine the differences in various distance speeds of the same swimmers; fourth, to determine the profiles of swimmers, based on the latent dimensions revealed.

\section{Methods}

Participants

A total of 68 male swimmers aged 14 to 16 from five Zagreb clubs were tested. All were participating in training programs in Zagreb swimming clubs. All participants were in good health, and they had been involved in swimming training process for the previous six years. They train six times per week, with the length of training of 2 hours. The testing was undertaken at swimming pools in Zagreb in a 25-m pool. Measurements were done in accordance with ethical principles, and all the tests were conducted by the same person. The testing procedure is standardized for all swimmers. 
Materials and Procedure

Swimmers were tested in specific motor skills. Four ST were used to measure speed (25-m freestyle, backstroke, breaststroke and butterfly), five ST measured speed endurance (50-m freestyle, 100-m freestyle, backstroke, breaststroke and butterfly), while only one test measured endurance (800-m freestyle) (Šiljeg, 2012). The $25-\mathrm{m}, 50-\mathrm{m}$ and $800-\mathrm{m}$ ST were used in the assessment of swimming speed applying the technique. The task was performed in the water at the starter's signal by pushing off from the wall. The result was measured with an Omega electronic device with one-hundredth-of-a-second accuracy. The 100-m results were taken at official swimming competitions in a 25-m length pool in the period of one month during the testing. Tests in the water were carried out in two phases, with a break of two days between testing for adequate recovery swimmers. The first phase consisted of the tests of speed $(25 \mathrm{~m})$ and speed endurance $(50 \mathrm{~m})$. Since the measuring was performed electronically, the swimmers first performed ST $25 \mathrm{~m}$ for all the techniques in the order: butterfly, backstroke, breaststroke and freestyle. The interval between each $25-\mathrm{m}$ swimming section of was 6 minutes. After this phase, the swimmers swam a maximum of 50-m freestyle (Šiljeg, 2012). After a twoday break, the swimmers performed ST 800-m with freestyle technique (Šiljeg, 2012).

\section{Statistical analysis}

The basic descriptive indicators for certain ST were calculated (means and standard deviations). Next, the latent dimensions on the standardized scores in ST (Z-scores) were determined, by using Principal Component Analysis (hereinafter PCA) with Varimax rotation, with the criteria of the interpretability of components obtained, along with the Guttman-Kaiser criterion and the Scree Plot. All ST were included in PCA for the first time and in the second PCA only chosen ST were. Cronbach alpha coefficients are used to determine internal consistency reliability of the latent dimensions obtained. The differences in certain swimming speeds in the same swimmers are determined using the nonparametric Friedman test. K-means cluster analysis is used in the taxonomization of standardized swimming speeds on various distances, using different swimming styles. For all the analyses, IBM SPSS 24.0 package was used. All differences and correlations are commented on the levels less than $\mathrm{p}<0.05$ and $\mathrm{p}<0.01$

\section{Results}

The results showed that two principal components (PCs) were obtained. The second PC describes the breaststroke swimming style only (on the distances 25 and $100 \mathrm{~m}$ ), while the first PC describes the correlations between all other swimming styles, on various distances (Table 1). In Table 2, there is a similar situation as in Table 1. For the results without tests of endurance (800-m freestyle), two PCs were obtained. One describes breaststroke swimmers, while the other (first) describes the correlations between all other swimming styles in both distances.

\begin{tabular}{|c|c|c|c|c|c|}
\hline \multirow{2}{*}{ Swimming styles } & \multicolumn{2}{|c|}{ Component } & \multirow{2}{*}{ Communalities } & \multirow{2}{*}{ Mean } & \multirow{2}{*}{ Std. Dev. } \\
\hline & 1 & 2 & & & \\
\hline 25-m free & .803 & .307 & .739 & 13.5 & 0.6 \\
\hline 25 - $m$ breast & & .933 & .874 & 18.5 & 1.2 \\
\hline 25-m back & .843 & & .713 & 15.9 & 1.1 \\
\hline $25-m$ fly & .832 & .306 & .786 & 15.3 & 1.2 \\
\hline 50- $m$ free & .740 & .362 & .678 & 28.8 & 1.5 \\
\hline 800-m free & .636 & .352 & .528 & 647.9 & 48.2 \\
\hline 100-m free & .876 & & .839 & 59.1 & 3.5 \\
\hline 100-m back & .871 & & .758 & 69.1 & 6.0 \\
\hline 100- $m$ breast & & .858 & .818 & 77.7 & 5.3 \\
\hline 100-m fly & .824 & & .724 & 69.8 & 6.7 \\
\hline Reliability (Cronbach's alpha) & 0.938 & 0.846 & & & \\
\hline Variance explained (\%) & 52.91 & 21.67 & & & \\
\hline Eigenvalues & 5.29 & 2.17 & & & \\
\hline
\end{tabular}

Legend: Bold - saturations in variables that define certain principal component.

The correlations between standardized speeds of the swimmers on various distances using different swimming styles confirm the fact that breaststroke style is relatively "isolated" from different swimming styles (Table 3); it is in lower correlation with other styles. The sizes of all correlations range from very low to high. The highest correlations are found between the scores in ST for the same style (discipline) in various distances. The lowest statistically significant correlation is between the 100-m breaststroke and 25-m backstroke. Quite different motor structure and length of swimming are the main reasons for the low correlation. The highest size of significant (positive) correlations between different disciplines is among the $100-\mathrm{m}$ fly and $100-\mathrm{m}$ freestyle. 
TABLE 2 Factor structure (Principal Component Analysis with Varimax rotation) of standardized swimming speeds on the distances of 100 metres and 25 metres

\begin{tabular}{|c|c|c|c|}
\hline \multirow{2}{*}{ Swimming styles } & \multicolumn{2}{|c|}{ Component } & \multirow{2}{*}{ Communalities } \\
\hline & 1 & 2 & \\
\hline 25-m free & .813 & .329 & .769 \\
\hline $25-m$ brest & & .938 & .884 \\
\hline 25-m back & .863 & & .744 \\
\hline $25-m$ fly & .840 & .327 & .812 \\
\hline $100-m$ free & .856 & & .802 \\
\hline 100-m back & .878 & & .772 \\
\hline $100-m$ breast & & .873 & .846 \\
\hline 100-m fly & .827 & & .736 \\
\hline Reliability (Cronbach's alpha) & 0.935 & 0.846 & \\
\hline Variance explained (\%) & 54.82 & 24.72 & \\
\hline Eigenvalues & 4.39 & 1.98 & \\
\hline
\end{tabular}

Legend: Bold - saturations in variables that define certain principal component

It can be explained by using the same motor structure of hand (full-scale "S" stroke). Among freestyle techniques, the highest correlation is found between ST on the distances $25-\mathrm{m}$ and 100-m freestyle. Between $50-\mathrm{m}$ freestyle and $100-\mathrm{m}$ freestyle, the correlation is similarly high as the correlations between $25-\mathrm{m}$ and $100-\mathrm{m}$ freestyle. The lowest correlation is found between $25-\mathrm{m}$ freestyle and $800-\mathrm{m}$ freestyle. Although it is the same technique, the lowest correlation can be explained by using different energy expenditure, according to lengthwise discipline.

\begin{tabular}{|c|c|c|c|c|c|c|c|c|c|c|}
\hline & $\begin{array}{l}25 m \\
\text { free }\end{array}$ & $\begin{array}{l}25 \mathrm{~m} \\
\text { back }\end{array}$ & $25 m$ & $\begin{array}{l}25 \mathrm{~m} \\
\text { breast }\end{array}$ & $\begin{array}{l}50 \mathrm{~m} \\
\text { free }\end{array}$ & $\begin{array}{l}800 m \\
\text { free }\end{array}$ & $\begin{array}{l}100 \mathrm{~m} \\
\text { free }\end{array}$ & $\begin{array}{l}100 \mathrm{~m} \\
\text { back }\end{array}$ & $\begin{array}{c}100 \mathrm{~m} \\
\text { breast }\end{array}$ & $\begin{array}{c}100 \mathrm{~m} \\
\text { fly }\end{array}$ \\
\hline 25-m free & 1 & $.657^{* * *}$ & $.748^{* *}$ & $.346^{* *}$ & $.652^{* *}$ & $.499^{* *}$ & $.791^{* *}$ & $.666^{* *}$ & $.481^{* *}$ & $.674^{* *}$ \\
\hline 25-m back & & 1 & $.708^{* *}$ & .115 & $.554^{* *}$ & $.374^{* *}$ & $.616^{* *}$ & $.798^{* *}$ & $.253^{*}$ & $.568^{* *}$ \\
\hline 25-m fly & & & 1 & $.363^{* *}$ & $.674^{* *}$ & $.534^{* * *}$ & $.733^{* * *}$ & $.633^{* *}$ & $.471^{* *}$ & $.848^{* *}$ \\
\hline 25-m breast & & & & 1 & $.377^{* *}$ & $.295^{*}$ & $.267^{*}$ & .107 & $.733^{* * *}$ & .216 \\
\hline 50-m free & & & & & 1 & $.646^{* *}$ & $.765^{* *}$ & $.581^{* *}$ & $.427^{* *}$ & $.607^{* *}$ \\
\hline 800-m free & & & & & & 1 & $.699^{* *}$ & $.524^{* * *}$ & $.414^{* *}$ & $.579^{* *}$ \\
\hline $100-\mathrm{m}$ free & & & & & & & 1 & $.741^{* *}$ & $.466^{* *}$ & $.778^{* *}$ \\
\hline 100-m back & & & & & & & & 1 & $.348^{* *}$ & $.618^{* *}$ \\
\hline 100-m breast & & & & & & & & & 1 & $.413^{* *}$ \\
\hline 100-m fly & & & & & & & & & & 1 \\
\hline
\end{tabular}

Legend: **significant at a level of $p<.01 ;{ }^{*}$ significant at a level of $p<.05$

Table 4 provides an insight into the differences between standardized (z-score) speeds of the swimmers on various distances using freestyle only. There are no relative differences in the median speed between the same swimmers who are swimming with the same style (freestyle) on different distances.

TABLE 4 Differences between standardized (z-score) speeds of the swimmers on various distances using free style only (paired samples)

\begin{tabular}{cccccc} 
Distance & $\mathbf{2 5} \mathbf{m}$ free & $\mathbf{5 0} \mathbf{m}$ free & $\mathbf{8 0 0} \mathbf{m}$ free & $\mathbf{1 0 0} \mathbf{m}$ free & Friedman test $(\mathbf{p})$ \\
\hline Median & .047 & -.135 & -.049 & -.058 & .757 \\
\hline
\end{tabular}

Table 5 provides an insight in the taxonomization of the standardized (z-score) speeds of the swimmers on various distances using all styles. The fourth cluster represents the swimmers who are the slowest, while the largest distance is found from the second cluster, where the swimmers are the fastest. The first and third clusters could not be similarly unambiguously explained, reflecting the interaction between swimming distances and styles. These two clusters are therefore very close. 


\begin{tabular}{|c|c|c|c|c|}
\hline & \multicolumn{4}{|c|}{ Cluster } \\
\hline & 1 & 2 & 3 & 4 \\
\hline 25 -m free & 0.152 & -0.933 & 0.735 & 2.502 \\
\hline 25-m back & -0.077 & -0.792 & 1.155 & 1.815 \\
\hline $25-m$ breast & 0.524 & -0.579 & -0.482 & 1.461 \\
\hline 25-m fly & 0.175 & -0.940 & 0.701 & 2.477 \\
\hline $100-m$ free & -0.049 & -0.739 & 0.774 & 2.786 \\
\hline 100-m back & -0.117 & -0.712 & 1.047 & 2.054 \\
\hline 100-m breast & 0.433 & -0.676 & -0.292 & 2.260 \\
\hline 100-m fly & 0.088 & -0.793 & 0.728 & 2.070 \\
\hline Number of Cases & 29 & 23 & 13 & 3 \\
\hline
\end{tabular}

Legend: Bold - scores for the fastest group.

\section{Discussion}

The results revealed that factor analysis without the test endurance and with it obtained two PCs. One principal component (in both cases) describes breaststroke (BS) swimmers, while the other one describes the correlations between all other swimming styles in various distances. This result can be explained by specifics of BS technique. BS is quite different than other strokes in certain anthropometric characteristics. Moreover, they are different according to their use of muscle categories, and the percentage of muscle usage while swimming BS in comparison to other swimming techniques. BS is the oldest, slowest, and most energy demanding of all swimming techniques (Barbosa et al, 2006). BS is the ancestor of butterfly and freestyle. BS is the appropriate technique to maintain on the water but it can be hard to learn, except for children who are "natural breaststroke swimmers". It is the least efficient of the four competitive strokes; swimmers encounter more frontal resistance in it than in any of the others (Hannula, 2003). The differences between BS and other strokes can be observed in the first movement after the swimmer leaves the wall. Their arms start first (in contrast with other strokes) and then kick during the latter part of the arm stroke. A single kick occurs during each stroke cycle. In BS, the movement of the arms and legs are symmetrical and they are carried out under the water. They simultaneously stroke with both hands and they have distinctive kick of the legs. Hand movement is diverse in comparison to other strokes in the propulsive phase and does not make a complete "S" stroke and does not have the last stroke phase (phase upsweep). Because of the specific simultaneous leg and hand work, swimmers have large deviation in a velocity during one stroke cycle. This is one of the reasons that BS is the slowest and most demanding technique. Even though a large propulsive force is created during the propulsive phase, there is a certain slow movement of the body going forward while preparing to kick with the legs. BS has the greatest intracyclic velocity variations of the four competitive strokes due to the underwater recoveries and the relatively long glide times (Seifert, Leblanc, Herault, Komar, Button \& Chollet, 2011; Leblanc, Seifert \& Chollet, 2009; Miyashita, 1974;). During these periods, the resistive forces are much greater than propulsive forces. With some swimmers, BS completely loses speed and they stop going forward while swimmers in the other competitive stroke lose only about one third of their forward velocity during recovery period in stroke cycles (Maglischo, 2003); the same author emphasizes that BS swimmers must create a much greater force than swimmers using other techniques, simply by accelerating their body forward to the competing velocity during the stroke cycle.

According to Montgomery and Chambers (2009), the BS has a certain degree of flexibility in the ankle, knee and hip that allows legs and feet to hold or grab more water while kicking. The legs are symmetrical and bent in the knee, at the same time and in the form of a triangle, with the feet turn outwards. What has been stated shows that, other than flexibility (Russel, 2015; Montgomery \& Chambers, 2009), a swimmer must have strong legs in order to produce a strong kick (Kippenhan, 2001; Strzala et al.,2012).

They have a specific way of breathing. Swimmers take a breath with every stroke cycle by raising the head and torso upwards and forwards. Extra force is used in the relaxation phase of the hand because, in the propulsive phase, it is going through the water and it begins to create extra resistance, which slows down the body when going forward. The structure of one's legs and feet may also play a role in becoming a good breaststroker, described by others as "walking like a duck" (Bixler, 2005).

Everything mentioned confirms that the BS technique is relatively "isolated" from different swimming styles. Consequently, the results that indicate the low correlation of BS technique with other styles on various distances were not unexpected. The lowest statistically significant correlation is found between $100-\mathrm{m} \mathrm{BS}$ and 25-m backstroke. This finding can be explained with completely different motor structures, body position and 
way of breathing in these two techniques, as well as with different energy exposure according to the length of duration of the ST. Because of all of these specific characteristics, many coaches say, "Breaststrokers are born not made" (Montgomery \& Chambers, 2009).

No relative differences in median speed between the same swimmers who are swimming on different distances in freestyle are found. The results of one swimmer to various distances lie in one direction, if it is swum with an even pace and at full power. This is the basis for calculating critical speed: swimming velocity at about maximal lactate steady state, expressed as yards or metres per second. When results are standardized, then it is expected that the differences of each swimmer in relation to the other swimmers on the $\mathrm{Z}$ scale are approximately the same (no significant difference). That was expected because specialization for swimmers in lengthwise swimming and technique begins at approximately the age of 16 . In this research we observed swimmers aged 14 to 16 and all had a training process that contains a lot of aerobic training and a lot of mixed swimming (Šiljeg, 2012). After the specialization of the swimmers in lengthwise distance, there is a change in the slope which improves the results of the individual distance and then an occurrence of statistical significant differences could be expected.

The advantage of this research is that all the swimmers from Zagreb swimming clubs are measured. Therefore, the sample of young swimmers is very representative of the population of Zagreb (Croatian) swimmers. Their achievements revealed unique work in all four swimming techniques, which could reflect coaches' good work in all clubs. Furthermore, there is no specialization among swimmers in freestyle swimming on various distances. Specific (specialized) training from an early age is not an indispensable precondition for later success; moreover, early participation in specific training programmes correlated negatively with long-term senior success (Vaeyens, Gullich, Chelsea, Warr \& Philippaerts, 2009).

The main shortcoming of the research is that the age range in the tested sample of swimmers is very large (3 years). Anderson, Hopkins, Roberts \& Pyne (2006) indicated a high variability in swimmers responses and results according to age. However, tested swimmers are undergoing a phase of accelerated growth and development, with possible large individual variations (Mišigoj, 2008), and it would be better if the swimmers in the same age could be observed separately.

For future studies, the authors suggest testing each age separately (Costa, 2016) as well as adding tests that control just legs (swimming with kickboard) and just hand work (swimming with pull-buoy). Furthermore, it would be interesting to do the testing in all phases (general, preparation, competition and relaxation) of the training process.

Practical implications of this research indicate that progress in the BS discipline is only controlled by the tests done while swimming BS. It is very important to apply a different practice program, which includes much work in BS technique if the improvement of the performance in BS discipline is to be accomplished. According to some research, leg work is the most responsible for propulsion swimming in the BS technique and must be the most represented in the training process of swimmers BS techniques (Maglischo, 2003). Swimmers' BS techniques in daily practice must have leg work three times more than in other techniques (Oxford et al., 2010). Considering swimmers age, it is necessary to apply specialization according to lengthwise swimming, especially among 16-year-old swimmers (Costa, Marinho, Reis, Silva, Bragada \& Barbosa, 2010).

\section{Conclusions}

The results revealed two interpretable and highly reliable latent dimensions of ST. Factor analysis of the ST differentiated the variables of ST that describe breaststrokes (BS) and other strokes (OS). Most of ST were positively correlated (in range $0.25-0.85$ ), while no differences in various distance speeds among the same swimmers are found. However, the correlations found between BS and OS are the lowest. Cluster analysis revealed clear profiles of the swimmers who are the slowest and those who are the fastest. However, the first and third clusters could not be similarly unambiguously explained, reflecting the interaction between swimming distances and styles (with the particular role of breaststroke swimming style). The results indicate the importance of using ST, especially in BS techniques, by developing different practice programs, which include specific approaches in BS technique training.

\section{REFEREN CES}

Anderson, M.E., Hopkins, W.G., Roberts, A.D., \& Pyne, D.B. (2006). Monitoring seasonal ad long-term changes in test performance in elite swimmers. European Journal of Sport Science, 6, 145-154.

Arellano, R. (2004). Applying biomechanical testing to swimming training. Seminario Europeo de Entrenadores de Natacion - Madrid. Retrieved August 5, 2015, from http://homepage.mac.com/ natacion/SwimmingScience/page4/page57/files/2004ArellanoEuroSem.pdf

Barbosa, T.M., Fernandes, R., Keskinen, K.L., Colaço, P., Cardoso, C., Silva, J., \& Vilas-Boas, J.P. (2006). Evaluation of the energy expenditure in competitive swimming strokes. Sports Medicine, 27(11), 894899.

Bixler, B.S. (2005). Resistance and propulsion. In: J.M. Stager, \& D.A. Tanner (Eds.): Swimming. Handbook 
of Sports Medicine and Science, 96. Massachusetts: Blackwell Science Ltd.

Brooks, R.W., Lance, C.C., \& Sawhill, J.A. (2000). Kicking is not a significant source of propulsion. The biomechanical interaction of lift and propulsion forces during swimming. Medical Science of Sports Exercise, 32(5), Supplement abstract 910.

Costa, M.J. (2016). Longitudinal interventions in elite swimming: relationship between energetics, biomechanics and performance. Doctoral Dissertation. Retrieved September 20, 2016 from http://repositorio.utad. $\mathrm{pt} / /$ handle/10348/5875.

Costa, M.J., Marinho, D.A., Reis, V.M., Silva, A.J., Bragada, J.A., \& Barbosa, T.M. (2010). Stability and prediction of $100 \mathrm{~m}$ Breaststroke performance during the elite swimmers career. In P.L. Kjendlie, R.K. Stallman, \& J. Cabri (Eds.). Proceedings of the XIth International Symposium on Biomechanics and Medicine in Swimming. Norway, pp. 272-273.

Grote, K, Lincoln, T.L., \& Gamble J.G. (2004). Hip adductor injury in competitive swimmers. The American Journal of Sports Medicine, 32, 104-108.

Hannula, D. (2003). Coaching swimming successfully. Champaign IL: Human Kinetics.

Havriluk, R. (2006). Magnitude of the effect of an instructional intervention on swimming technique and performance. In J. P. Vilas-Boas, F. Alves, A. Marques (Eds.), Biomechanics and Medicine in Swimming X. Portuguese Journal of Sport Sciences, 6(S2), 218-220.

Keskinen, K., Eriksson, E., \& Komi, P. (1980). Breaststroke swimmer's knee: Abiomechanical and arthroscopic study. The American Journal of Sports Medicine, 8, 228-231.

Latt, E., Jurimae, J., Maestu, J., Purge, P., Ramson, R., Haljaste, K., Keskinen, K.L., Rodrigez, F.A., \& Jurimae, T. (2010). Physiological, biomechanical and anthropometrical predictors of sprint swimming performance in adolescent swimmers. Journal of Sports Science and Medicine, 9, 398-404.

Leblanc, H., Seifert, L., \& Chollet, D. (2009). Arm-leg coordination in recreational and competitive breaststroke swimmers. Journal of Science and Medicine in Sport, 12, 352-356.

Leko, G., Šiljeg, K., \& Zoretić, D. (2011). Predictors on performance in swimming strokes. 5th ISN International Sports Medicine and Sports Science Conference. Kuala Lumpur.

Kippenhan, B.C. (2001). Influence of lower extremity joint motions of the effectiveness of the kick in breaststroke swimming. In: J.R. Blackwel, \& R.H. Sanders (Eds.) Proceedings of swim sessions: XIX International Symposium on Biomechanics in Sports, 48-52. San Francisco, CA.

Maglischo, E.W. (2003). Swimming fastest. California, London, Toronto: Mayfield Publishing Company Mountain.

Mišigoj-Duraković, M. (2008). Kinantropologija. Biološki aspekti tjelesnog vježbanja. Zagreb: Kineziološki fakultet Sveučilišta u Zagrebu.

Montgomery, J., \& Chambers, M. (2009). Mastering swimming. Champaign IL: Human Kinetics.

Miyashita, M. (1974). Method of calculating mechanical power in swimming the breast stroke. Research Quarterly, 45(2), 128-137.

Nelson, B., Pyne, D., \& Sweetenham, B. (1991). National talent identification and development program for swimming. Paper presented as the 1999 ASCTA Convention. Western Australian Institute of Sport. Retrieved September 11, 2011, from http://www.wasa.asn.au/html/coaching/rtf/tid-ascta.rtf.

Nuber, G.W., Jobe, F.W., Perry, J., Moynes, D.R., \& Antonelli, D. (1986). Fine wire electromyography analysis of muscles of the shoulder during swimming. The American Journal of Sports Medicine, 14, 7-11.

Olbrecht, J. (2000). The Science of Winning. Luton, England: Swimshop.

Oxford, S. W., James, R., Price, M., \& Payton, C. (2010). Coordination changes during a maximal effort $100 \mathrm{~m}$ short-course breaststroke swim. XIth International Symposium for Biomechanics and Medicine in Swimming, Oslo: Norwegian School of Sport Sciences.

Richards, R. (1999). Talent identification and development. ASCTA Convention. Australia.

Russel, M. (2015). Butterfly Technique. In S. Riewald, S. \& Rodeo (Eds). Science of Swimming Faster, 87-96. Champaign: Human Kinetics.

Seifert, L., Leblanc, H., Herault, R., Komar, J., Button, C., \& Chollet, D. (2011). Inter-individual variability in the upper-lower limb breaststroke coordination. Human Movement Science, 3, 550-565.

Smith, D. J., Norris, S., \& Hogg, J., M. (2002). Performance Evaluation of Swimmers. Sports Medicine, 32(9), 539-554.

Soons, B., Silva, A., Colman, V., \& Persyn, U. (2003). Specific movement variables important for performance in different breaststroke styles. In J.C. Chatard (Ed.) IX. International Symposium for Biomechanics and Medicine in Swimming, 295. St. Etienne: Publications de l'Université de St. Etienne.

Sokolovas, G. (2006). Analysis of swimming's all-time top 100 times. In: J.P. Vilas-Boas, F., \& Alves, A. Marques (Ed). Xth International Symposium on Biomechanics and Medicine in Swimming, 315-317. Porto: University of Porto.

Strzała, M., Krężałek, P., Kaca, M., Głąb ,G., Ostrowski, A., Stanula, A., \& Tyka, A. (2012). Swimming Speed of The Breaststroke Kick. Journal of Human Kinetics, 35, 133-139.

Sweetenham, B. \& Atkinson, J. (2003). Championship swim training. Champaign IL: Human Kinetics.

Šiljeg, K. (2012). Povezanost antropoloških karakteristika i specifičnih plivačkih sposobnosti s uspješnošću u plivanju. Doctoral Dissertation. Zagreb: Kineziološki fakultet.

Thorton, N. (2012). Trends and techniques in breaststroke. In: D. Hannula, N., \& Thorton, (Eds). The swim coaching Bible, pp. 184-198. Champaign IL: Human Kinetics. 
Vaeyens, R., Güllich, A., Chelsea, R., Warr, C.R., \& Philippaerts, R. (2009). Talent identification and promotion programmes of Olympic athletes. Journal of Sports Sciences, 27(13), 1367-1380.

Vorontsov, A.R. (2002). Multi-year training of young athlete as potential modifier of growth and development (Analysis of some biological concepts). Sport Medicine in Aquatic Sports - the XXI Century, FINA World Sport Medicine. 